\title{
Lifetime mental disorders and suicidal behaviour in South Africa
}

\author{
L Khasakhala ${ }^{1,2}$, KR Sorsdahl'3, VS Harder,4, DR Williams ${ }^{5}$, DJ Stein ${ }^{3}$, DM Ndetei1,2 \\ ${ }^{1}$ University of Nairobi, Nairobi, Kenya \\ ${ }^{2}$ Africa Mental Health Foundation, Nairobi, Kenya \\ 3University of Cape Town, Cape Town, South Africa \\ 4University of Vermont, Burlington VT, United States of America \\ 5Harvard University, Boston MA, United States of America
}

\begin{abstract}
Background: There is relatively little data on the relationship between lifetime mental disorders and suicidal behaviour in low and middle income countries. This study examines the relationship between lifetime mental disorders, and subsequent suicide ideation, plans, and suicide attempts in South Africa. Method: A national survey of 4185 South African adults was conducted using the World Health Organization Composite International Diagnostic Interview (CIDI) to generate psychiatric diagnoses and suicidal behaviour. Bivariate, multivariate and discrete-time survival analyses were employed to investigate the associations between mental disorders and subsequent suicide ideation, plans, and attempts. Results: Sixty-one percent of people who seriously considered killing themselves at some point in their lifetime reported having a prior DSM-IV disorder. Mental disorders predict the onset of suicidal ideation, but have weaker effects in predicting suicide plans or attempts. After controlling for comorbid mental disorders, PTSD was the strongest predictor of suicidal ideation and attempts. There is a relationship between number of mental disorders and suicidal behaviour, with comorbidity having significantly sub-additive effects. Conclusion: Consistent with data from the developed world, mental disorders are strong predictors of suicidal behaviour, and these associations are more often explained by the prediction of ideation, rather than the prediction of attempts amongst ideators. This suggests some universality of the relevant mechanisms underlying the genesis of suicidal thoughts, and the progression to suicide attempts.
\end{abstract}

Key Words: Suicide; Survey; South Africa; Mental Disorders

Received: 03-02-2010

Accepted: 13-04-2010

doi: $10.4314 /$ ajpsy.v14i2.5

\section{Introduction}

Suicidal behaviour is among the leading causes of death and disease burden around the world. ${ }^{1}$ The World Health Organization (WHO) estimates that in 2002 alone, approximately 877,000 deaths worldwide were due to suicide ${ }^{2}$, making it an important worldwide public health concern in both the developed and developing world. Although there is an abundance of epidemiological research on the prevalence of suicide from the developed world ${ }^{3,4}$, limited data exists from less developed countries. However, recently data from a nationally representative sample in South

\section{Correspondence}

Dr. K Sorsdahl

Department of Psychiatry \& Mental Health, J-2 Groote Schuur Hospital,

Observatory, Cape Town, 7925, South Africa

email: kattsorsdahl@gmail.com
Africa revealed comparable estimated lifetime prevalence of suicide ideation (9.1\%), plans (3.8\%), and attempts (2.9\%) to more developed countries. ${ }^{5}$

Although the etiology of suicide is not well-understood, numerous studies in developed countries have found that mental disorders, particularly depressive disorders, are one of the strongest risk factors for suicide attempts and suicide deaths. ${ }^{6}$ This risk has also shown to decline after treatment and recovery. ${ }^{7}$ Nevertheless, as most studies have considered only one disorder, it is not exactly clear which mental disorders predict suicidal behaviours. For example, findings on the role of panic disorder in predicting suicide attempts are altered when controlling for a range of comorbid disorders. ${ }^{8,9}$ To obtain a better understanding of the direct relationship between mental disorders and suicidal behaviour, studies accounting for the effects of co-occuring mental disorders are essential. 
The relationship between prior mental disorders and subsequent suicide has been primarily studied in the developed world ${ }^{4,10}$, with little data from low and middle income countries. ${ }^{11}$ It is possible that in developing countries different predictors of suicide ideation genesis and progression may be in operation. ${ }^{12,13}$ The development of adequate screening, prevention and intervention tools in such countries would benefit from a more in depth understanding of mental disorders as a risk factor for suicide.

There are also few data on the extent to which the associations between mental disorders and suicide attempts are mediated by suicide ideation and plans. The few studies that have investigated these issues suggest that mental disorders predict the onset of suicide ideation, but may have weaker effects in predicting suicide plans or attempts among people with suicide ideation. ${ }^{4,14,15} \mathrm{~A}$ clearer understanding of successful interventions and treatment would be achieved by mapping the relationships between identified mental disorders and progressive stages of suicide ideation - however, there is very little data to draw from in this area from the developing world.

Existing data from the South African Stress and Health Study (SASH) investigating the prevalence and correlates of suicide behaviour reveal that having a mental disorder is a risk factor for a lifetime suicide attempt. Respondents with at least one DSM-IV disorder were four times (95\% CI 2.6-6.2) more likely to attempt suicide than those with no disorder. ${ }^{5}$ Respondents with three or more disorders were eight times more likely to attempt suicide $(\mathrm{OR}=8.3$, 95\% CI 4.8-14.2) and to develop suicidal ideation $(\mathrm{OR}=8.3,95 \% \mathrm{CI} 4.3-15.8)$ than were respondents with no psychiatric disorder. Here we extend that work by exploring the effects of co-occuring disorders in more detail, and by delineating the significant associations established through the mediators of suicide ideation.

\section{Method}

The South African Stress and Health (SASH) study ${ }^{16}$ was undertaken as part of the World Mental Health Survey ${ }^{17}$ to investigate the prevalence of mental disorders in the South African context. The survey was conducted between January 2002 and June 2004. The rationale and survey methods have been detailed previously ${ }^{16}$ and are briefly summarized here. Ethical approval was provided by the University of Michigan, Harvard Medical School, and by a single project assurance of compliance from the Medical University of South Africa that was approved by the National Institute of Mental Health.

The study population included South Africans who resided in both households and hostels and were a minimum of 18 years old. The sample excluded those individuals living in institutions (including hospitals, prisons, mental health institutions and military bases). The sample was selected using a multi-stage area probability sample design. The first stage involved selecting a stratified probability sample of primary sampling areas equivalent to counties in the US or the UK based on the 2001 South African Census of Enumeration Areas (EAs). The EAs were sampled with probabilities proportionate to population size. Second, within each EA a random sample of 5 households was selected and finally the third stage consisted of a random sub-selection of a single adult responded in each selected sample housing unit.

Up to three attempts were made to contact each respondent selected to participate. The overall response rate was $85 \%$ and the final sample consisted of 4351 individuals. The SASH interviewers received intensive training for one week in centralized group sessions. The face-to-face interviews lasted approximately three and a half hours, although a number of interviews required more than one visit to complete. The interviews were conducted in one of several local languages.

\section{Measures}

A modified version of the World Mental Health Composite International Diagnostic Interview (WMH-CIDI), a fully structured diagnostic interview administered by trained lay interviewers was used to assess lifetime and 12-month DSM-IV disorders. ${ }^{18}$ These DSM-IV disorders included anxiety disorders (panic disorder, agoraphobia, social phobia, generalized anxiety disorder and posttraumatic stress disorder), mood disorders (major depressive disorder), substance use disorders (alcohol and drug abuse and dependence), and disorders associated with impulse control (intermittent explosive disorder (IED).

Suicidal behaviours were assessed using the Suicidality Module of the CIDI. ${ }^{18}$ This module includes an assessment of the lifetime occurrence and age-of-onset of suicide ideation, plans, and attempts. We considered five dated lifetime history outcomes in a series of nested survival analyses (see below for analysis methods): (i) suicide ideation in the total sample; (ii) suicide attempt in the total sample; (iii) suicide plan among respondents with ideation; (iv) suicide attempt among those with a plan; and (v) suicide attempt among those with ideation in the absence of a plan (impulsive attempt).

\section{Analysis of Data}

Prevalence of temporally prior mental disorders among respondents with each of the five outcomes was estimated using cross-tabulations. Temporal priorities of mental disorders were examined using individual-level retrospective age-of-onset reports. Predictive associations between temporally prior mental disorders and subsequent suicidal behaviours were estimated using discrete-time survival models with person-years as the unit of analysis. Mental disorders were treated as timevarying covariates in these models. Survival coefficients were exponentiated to generate odds-ratios (ORs) and their standard errors for ease of interpretation.

The survival models included bivariate models in which only one mental disorder was considered at a time as well as multivariable models that included all mental disorders simultaneously to predict each outcome. We also estimated a series of models that allowed for multiplicative interactions among comorbid disorders. We began with a model that included summary dummy predictor variables for total number of comorbid disorders experienced by each respondent (e.g., separate dummy predictor variables to distinguish respondents with exactly two 
disorders and exactly three or more disorders). Standard errors of prevalence estimates and survival coefficients were estimated with the Taylor series method ${ }^{19}$ using SUDAAN software ${ }^{20}$ to adjust for the weighting and clustering of the NCS-R sample design. Multivariate significance was evaluated with Wald $\chi 2$ tests based on design-corrected coefficient variance-covariance matrices. All significance tests were evaluated using .05-level twosided tests.

\section{Results}

Prevalence of temporally primary disorders among those with suicidal behaviours

Sixty-one percent of the total sample that reported suicidal ideation also reported having a prior lifetime DSM-IV disorder. History of any mental disorder was even higher among respondents who went on to make a suicide plan (64.0\%) and to make a suicide attempt (70.3\%). (Table I)

\section{Associations of temporally primary DSM-IV/CIDI disorders with suicide attempts}

Bi-variate survival models revealed that with the exception of agoraphobia, all the remaining nine mental disorders investigated in the SASH study were significantly associated with increased odds of the subsequent first onset of a suicide attempt. ORs for the specific disorders range from a low of 2.7 (IED) to a high of 7.2 (PTSD) (Table II). The bivariate ORs associated with broad classes of disorder were similar: 3.7 for any anxiety disorder; 3.3 for any mood disorder; 3.3 for any impulse-control disorder; and 4.8 for any substance use disorder. The bivariate OR associated with having any disorder was also relatively high (4.5).

These ORs all decrease in additive multivariable models that test the unique associations between disorders and suicide attempt, where only major depression $(\mathrm{OR}=1.8)$, social phobia $(\mathrm{OR}=3.3$ ), panic disorder $(\mathrm{OR}=4.7)$, and PTSD $(\mathrm{OR}=4.9)$ remain statistically significant. A simple interactive multivariate model was also considered in which predictors included the 9 dummy variables for individual types of disorders plus additional dummy variables for number of disorders (e.g., a dummy variable for respondents who had exactly two prior lifetime disorders, a separate dummy variable for respondents with exactly three such disorders, etc.). The ORs for individual disorders in this interactive model can be interpreted as the relative-odds of a subsequent suicide attempt among respondents with a history of a pure disorder (i.e., only this one disorder) versus those with no disorders. This more complex model shows that all disorders are significantly associated with suicide attempts (ORs in the range 3.1-7.3), with PTSD (OR=8.5), panic disorder $(\mathrm{OR}=7.3)$ and social phobia $(\mathrm{OR}=6.9)$ having the strongest associations.

Table I: Prevalence of Lifetime DSM-IV Disorders Among Adults with Suicidal Behaviour

\begin{tabular}{|c|c|c|c|c|c|c|c|c|c|c|c|c|c|c|c|c|c|c|}
\hline & \multicolumn{6}{|c|}{ Among total sample } & \multicolumn{6}{|c|}{ Among ldeators } & \multicolumn{6}{|c|}{ Among total sample } \\
\hline & \multicolumn{3}{|c|}{ Attempt } & \multicolumn{3}{|c|}{ No attempt } & \multicolumn{3}{|c|}{ Plan } & \multicolumn{3}{|c|}{ No plan } & \multicolumn{3}{|c|}{ Ideation } & \multicolumn{3}{|c|}{ No ideation } \\
\hline & N2 & $\% 3$ & SE & N2 & $\% 3$ & SE & N2 & $\% 3$ & $S E$ & N2 & $\% 3$ & $S E$ & N2 & $\% 3$ & $S E$ & N2 & $\% 3$ & $S E$ \\
\hline Panic Disorder & 9 & 6.8 & 2.4 & 48 & 1.1 & 0.2 & 11 & 6.4 & 2.0 & 8 & 2.7 & 1.3 & 19 & 4.2 & 1.0 & 38 & 0.9 & 0.2 \\
\hline GAD & 20 & 14.1 & 3.2 & 147 & 3.3 & 0.4 & 27 & 17.4 & 3.2 & 18 & 7.9 & 2.6 & 45 & 11.8 & 2.1 & 122 & 2.8 & 0.3 \\
\hline Social Phobia & 17 & 13.0 & 4.3 & 99 & 2.5 & 0.4 & 16 & 9.2 & 3.2 & 21 & 7.7 & 1.8 & 37 & 8.3 & 1.7 & 79 & 2.3 & 0.4 \\
\hline Post-Traumatic Disorder & 14 & 8.8 & 2.6 & 77 & 2.1 & 0.3 & 15 & 7.7 & 2.1 & 11 & 6.4 & 2.5 & 26 & 6.9 & 2.0 & 65 & 1.8 & 0.3 \\
\hline Agoraphobia & 26 & 15.4 & 2.9 & 409 & 9.7 & 0.6 & 31 & 16.4 & 3.8 & 40 & 13.4 & 2.8 & 71 & 14.7 & 2.1 & 364 & 9.3 & 0.6 \\
\hline Any Anxiety Disorder & 59 & 39.4 & 4.6 & 658 & 15.7 & 0.8 & 67 & 37.8 & 4.7 & 70 & 27.3 & 3.6 & 137 & 31.7 & 2.9 & 580 & 14.8 & 0.7 \\
\hline Major Depression & 38 & 27.1 & 4.0 & 401 & 9.3 & 0.7 & 44 & 26.1 & 3.6 & 52 & 21.8 & 3.3 & 96 & 23.6 & 2.1 & 343 & 8.4 & 0.7 \\
\hline Dysthymia & 1 & 1.8 & 1.7 & 0 & 0.0 & 0.0 & 1 & 1.4 & 1.3 & 0 & 0.0 & 0.0 & 1 & 0.6 & 0.6 & 0 & 0.0 & 0.0 \\
\hline Any Mood & 38 & 27.1 & 4.0 & 401 & 9.3 & 0.7 & 44 & 26.1 & 3.6 & 52 & 21.8 & 3.3 & 96 & 23.6 & 2.1 & 343 & 8.4 & 0.7 \\
\hline $\mathrm{IED}$ & 14 & 11.0 & 3.3 & 93 & 2.8 & 0.4 & 15 & 11.4 & 3.2 & 21 & 12.3 & 3.0 & 36 & 11.9 & 2.6 & 71 & 2.1 & 0.4 \\
\hline Any Impulse & 14 & 11.0 & 3.3 & 72 & 2.9 & 0.4 & 15 & 11.4 & 3.2 & 16 & 9.8 & 2.9 & 36 & 11.9 & 2.6 & 55 & 2.4 & 0.4 \\
\hline Alcohol Abuse or Dependence & 38 & 29.9 & 3.7 & 397 & 10.8 & 0.8 & 45 & 29.1 & 5.2 & 44 & 23.0 & 4.9 & 89 & 25.5 & 3.7 & 346 & 9.9 & 0.7 \\
\hline Drug Abuse or Dependence & 15 & 13.0 & 3.0 & 124 & 3.6 & 0.4 & 25 & 19.0 & 5.1 & 6 & 3.8 & 1.7 & 31 & 10.1 & 2.1 & 108 & 3.3 & 0.4 \\
\hline Any Substance Disorder & 41 & 32.3 & 4.0 & 464 & 12.8 & 0.9 & 52 & 34.3 & 5.8 & 46 & 24.3 & 4.9 & 98 & 28.5 & 3.5 & 407 & 11.8 & 0.8 \\
\hline Any Disorder & 95 & 70.3 & 4.5 & 1221 & 29.8 & 1.2 & 107 & 64.0 & 4.1 & 129 & 58.9 & 4.6 & 236 & 61.0 & 3.0 & 1080 & 28.0 & 1.1 \\
\hline Exactly 1 & 42 & 30.0 & 3.9 & 803 & 19.0 & 0.8 & 39 & 20.9 & 3.2 & 72 & 33.3 & 4.0 & 111 & 28.1 & 2.8 & 734 & 18.5 & 0.8 \\
\hline Exactly 2 & 24 & 18.8 & 4.5 & 296 & 7.4 & 0.5 & 32 & 20.2 & 3.6 & 30 & 14.3 & 2.7 & 62 & 16.7 & 2.1 & 258 & 6.9 & 0.5 \\
\hline 3 or more & 29 & 21.5 & 4.4 & 122 & 3.4 & 0.6 & 36 & 23.0 & 5.5 & 27 & 11.4 & 2.9 & 63 & 16.2 & 3.2 & 88 & 2.7 & 0.4 \\
\hline (N)1 & & (140) & & & (4175) & & & (171) & & & (223) & & & (394) & & & (3921) & \\
\hline \multicolumn{19}{|c|}{$\begin{array}{l}{ }^{1} \text { Number of cases with the outcome variable } \\
{ }^{2} \text { Numerator N. Number of cases with the LT disorder among cases with the outcome variable. Columns with "Yes" in the headers represents cases with the } \\
\mathrm{dx} \text { among those with the outcome, and columns with "No" represents among those without the outcome } \\
3 \% \text { represents the percentage of people with the DSM-IV disorder among the cases with the outcome variable indicated in the column header. For example: } \\
\text { the first cell is the \% of those with Panic disorders among those with attempts }\end{array}$} \\
\hline
\end{tabular}


Table II. Multivariate Associations Between Lifetime Suicide Attempts and Lifetime DSM-IV disorders

\begin{tabular}{|c|c|c|c|c|}
\hline & \multicolumn{4}{|c|}{ Response variable: Lifetime Suicide Attempt among total sample=4315 } \\
\hline & \multicolumn{2}{|c|}{ Bivariate models with each disorder in separate mode/ ${ }^{7}$} & \multicolumn{2}{|c|}{ Multivariable models with all disorders in the same mode/ ${ }^{1}$} \\
\hline & OR $(95 \% \mathrm{Cl})$ & Chi square & OR $(95 \%$ Cl) & Chi square \\
\hline $\begin{array}{l}\text { Panic Disorder } \\
\text { General Anxiety Disorder } \\
\text { Social Phobia } \\
\text { Post-traumatic Stress } \\
\text { Agoraphobia } \\
\text { Any Anxiety Disorder } \\
\text { Major Depressive Disorder } \\
\text { Any Mood Disorder } \\
\text { IED } \\
\text { Any Impulse Disorder } \\
\text { Alcohol abuse or dependence } \\
\text { drug abuse or dependence } \\
\text { Any Substance Disorder } \\
\text { Any Disorder }\end{array}$ & $\begin{array}{l}6.9^{\star}(2.4-20.2)^{\star} \\
4.6^{\star}(2.0-10.8)^{\star} \\
5.7^{\star}(2.6-12.3)^{\star} \\
7.2^{\star}(3.1-16.5)^{\star} \\
1.5(0.8-2.8) \\
3.7^{\star}(2.3-5.9)^{\star} \\
3.3^{\star}(1.9-5.6)^{\star} \\
3.3^{\star}(1.9-5.6)^{\star} \\
2.7^{\star}(1.1-6.9)^{\star} \\
2.7^{\star}(1.1-6.9)^{\star} \\
3.6^{\star}(2.0-6.4)^{\star} \\
4.5^{\star}(2.2-9.0)^{\star} \\
3.7^{\star}(2.2-6.1)^{\star} \\
4.5^{\star}(2.9-6.8)^{\star}\end{array}$ & $\begin{array}{l}13.1(<.001)^{\star} \\
12.9(<.001)^{\star} \\
20.6(<.001)^{\star} \\
22.7(<.001)^{\star} \\
1.9(0.16) \\
32.0(<.001)^{\star} \\
20.3(<.001)^{\star} \\
20.3(<.001)^{\star} \\
4.4(0.035)^{\star} \\
4.4(0.035)^{\star} \\
19.8(<.001)^{\star} \\
18.8(<.001)^{\star} \\
26.6(<.001)^{\star} \\
50.0(<.001)^{\star}\end{array}$ & $\begin{array}{l}4.7^{\star}(1.5-14.3)^{\star} \\
2.2(0.7-6.2) \\
3.3^{\star}(1.3-8.7)^{\star} \\
4.9^{\star}(2.1-11.7)^{\star} \\
1.1(0.6-2.0) \\
1.8^{\star}(1.1-3.2)^{\star} \\
1.5(0.5-4.4) \\
2.0(0.9-4.3) \\
2.4(0.9-6.2)\end{array}$ & $\begin{array}{l}7.4(0.006)^{\star} \\
2.1(0.15) \\
6.1(0.014)^{\star} \\
13.7(<.001)^{\star} \\
0.1(0.72) \\
4.8(0.029)^{\star} \\
0.5(0.49) \\
2.9(0.09) \\
3.5(0.06)\end{array}$ \\
\hline Overall Group Effect Chisquare² & & & & $162.8(<.001)^{\star}$ \\
\hline \multicolumn{5}{|c|}{$\begin{array}{l}\text { * Significant at the .05 level, two-sided test. Highlighted rows indicates the disorder specified in the row was not included in the model. } \\
1 \text { Models are all in survival framework and all control for age, age-squared, sex, cohorts, and int categories. Int categories have cut-off points of 1-5,6-10,11 } \\
15, \ldots . .70-75 \text { up to largest int available in dataset } \\
2 \text { Group effect chi square is for the multi-df tests to assess any difference between all the \# of disorder dummies, while the individual chi-squares only tests } \\
\text { yes vs no for each }\end{array}$} \\
\hline
\end{tabular}

\section{Associations of number of comorbid disorders with suicide attempts}

The association between psychiatric comorbidity and suicide attempts was examined by estimating a model in which the only substantive predictors were dummy variables for the number of disorders temporally prior to the first suicide attempt. A strong positive association was found between these predictors and subsequent suicide attempt, with ORs ranging from a low of 3.7 for one disorder, 6.1 for two, and 8.8 for three (compared to respondents with no disorders). (Table III). The effects of additional disorders were, however sub-additive, with additional disorders having diminishing effects, with a prevalence of suicide attempts of $30.0 \%$ in those with 1 disorder, $18.8 \%$ with two and $21.5 \%$ with three disorders attempted suicide. In order words, the relative-odds of suicide attempts increase at a decreasing rate as the numbers of comorbid disorders increase.

Models investigating the co-morbidities of lifetime suicidality with lifetime DSM-IV mental disorders and number of disorders revealed that the most predictive associations were with suicide ideation, but many mental disorders and comorbidity patterns also predicted suicide attempt (Table IV). Only PTSD (OR= 5.3, CI 1.6-7.5) and substance abuse or dependence (OR=5.2, CI 2.2-12.1) predicted a suicide plan among ideators. Interestingly, when numbers of other co-morbid disorders was controlled for, ORs for exactly two disorders and for three or more disorders were significantly less than 1.0 in predicting suicide ideation, and the OR for three or more disorders was significantly less than 1.0 in predicting suicide attempt (Table IV). This sub-additive comorbidity involving numbers of disorders was not found in predicting plans among ideators, where ORs for exactly 2 and 3 or more disorders were closer to 1.0 and not significant. An examination of the predictive associations of individual disorders reveals that PTSD was amongst the strongest predictors of suicide attempts $(\mathrm{OR}=8.6)$, but was less predictive for suicide ideation $(\mathrm{OR}=4.4)$. The most significant predictors of suicide ideation were IED $(\mathrm{OR}=6.4)$ and panic disorder $(\mathrm{OR}=6.1)$, after controlling for number of comorbid disorders. (Table IV).

\section{Discussion}

The results of the present study advance our understanding about suicidal behaviour in South Africa in a number of ways. To begin with, 61\% of South Africans who seriously considered killing themselves and 70\% who actually made a suicide attempt were found to have a prior mental disorder. Bivariate analyses revealed that individuals suffering from any one of the 9 mental

\begin{tabular}{|c|c|c|}
\hline & \multirow{2}{*}{\multicolumn{2}{|c|}{\begin{tabular}{|l} 
Response variable: Lifetime Attempt \\
among total sample=4315
\end{tabular}}} \\
\hline & & \\
\hline & OR (95\% Cl) & Chi-square \\
\hline $\begin{array}{l}1 \text { Disorder } \\
2 \text { Disorders } \\
3 \text { or more Disorders } \\
\text { Overall Group Effect Chisquare } \\
\text { for number of disorders² }\end{array}$ & $\begin{array}{l}3.7^{\star}(2.3-5.8)^{\star} \\
6.1^{\star}(3.0-12.6)^{\star} \\
8.8^{\star}(4.2-18.2)^{\star}\end{array}$ & $\begin{array}{l}31.8(<.001)^{\star} \\
25.4(<.001)^{\star} \\
35.4(<.001)^{\star} \\
63.8(<.001)^{\star}\end{array}$ \\
\hline
\end{tabular}


Table IV. Association Between Lifetime Suicidal Behaviour and Lifetime DSM-IV Mental Disorders Accounting for Number of Comorbid Disorders ${ }^{1}$

\begin{tabular}{|c|c|c|c|c|c|c|}
\hline & \multicolumn{2}{|c|}{ Suicide Attempt among Total Sample } & \multicolumn{2}{|c|}{ Suicide Plan among Ideators } & \multicolumn{2}{|c|}{ Suicide Ideation among Total Sample } \\
\hline & OR $(95 \% \mathrm{Cl})$ & Chi square & OR $(95 \% \mathrm{Cl})$ & Chi square & OR $(95 \% \mathrm{Cl})$ & Chi square \\
\hline $\begin{array}{l}\text { Panic Disorder } \\
\text { General Anxiety Disorder } \\
\text { Social Phobia } \\
\text { Post-traumatic Stress } \\
\text { Agoraphobia } \\
\text { Major Depressive Disorder } \\
\text { IED } \\
\text { Alcohol abuse or dependence } \\
\text { drug abuse or dependence } \\
\text { Exactly } 2 \text { Disorders } \\
3 \text { or more Disorders } \\
\text { Overall Group Effect Chisquare } \\
\text { for disorders }{ }^{2} \\
\text { Overall Group Effect Chisquare } \\
\text { for number of other disorders }\end{array}$ & $\begin{array}{l}7.3^{\star}(2.0-26.6)^{\star} \\
4.5^{\star}(1.3-15.7)^{\star} \\
6.9^{\star}(2.5-18.7)^{\star} \\
8.5^{\star}(3.1-23.6)^{\star} \\
1.6(0.9-2.7) \\
3.1^{\star}(1.6-5.7)^{\star} \\
2.2(0.6-7.8) \\
3.4^{\star}(1.6-7.1)^{\star} \\
4.3^{\star}(1.5-12.1)^{\star} \\
0.5(0.1-1.4) \\
0.1^{\star}(0.0-0.5)^{\star}\end{array}$ & $\begin{array}{l}9.5(0.002)^{\star} \\
5.8(0.016)^{\star} \\
14.8(<.001)^{\star} \\
17.5(<.001)^{\star} \\
2.8(0.10) \\
12.7(<.001)^{\star} \\
1.6(0.21) \\
10.9(<.001)^{\star} \\
7.7(0.006)^{\star} \\
1.8(0.18) \\
7.9(0.005)^{\star} \\
46.3(<.001)^{\star} \\
8.2(0.016)^{\star}\end{array}$ & $\begin{array}{l}1.6(0.4-6.8) \\
2.4(1.0-5.9) \\
1.3(0.5-3.4) \\
5.3^{\star}(1.6-17.5)^{\star} \\
1.7(0.7-4.1) \\
1.3(0.8-2.4) \\
1.2(0.5-2.9) \\
1.7(0.8-3.4) \\
5.2^{*}(2.2-12.1)^{\star} \\
0.7(0.3-1.5) \\
0.3(0.1-1.0)\end{array}$ & $\begin{array}{l}0.4(0.54) \\
3.8(0.05) \\
0.4(0.54) \\
7.9(0.005)^{\star} \\
1.7(0.19) \\
1.0(0.32) \\
0.3(0.62) \\
1.9(0.17) \\
14.8(<.001)^{\star} \\
0.8(0.38) \\
3.8(0.05) \\
27.8(0.001)^{\star} \\
4.5(0.11)\end{array}$ & 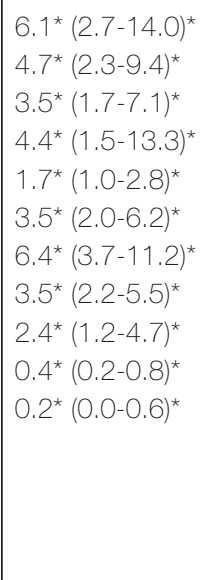 & $\begin{array}{l}19.0(<.001)^{\star} \\
19.3(<.001)^{\star} \\
12.0(<.001)^{\star} \\
7.2(0.007)^{\star} \\
4.3(0.038)^{\star} \\
19.2(<.001)^{\star} \\
44.3(<.001)^{\star} \\
28.8(<.001)^{\star} \\
5.9(0.015)^{\star} \\
6.6(0.010)^{\star} \\
7.7(0.006)^{\star} \\
113.6(<.001)^{\star} \\
8.0(0.019)^{\star}\end{array}$ \\
\hline$(\mathrm{N})^{4}$ & \multicolumn{2}{|l|}{$(4315)$} & \multicolumn{2}{|l|}{ (394) } & \multicolumn{2}{|l|}{ (4315) } \\
\hline \multicolumn{7}{|c|}{$\begin{array}{l}\text { * Significant at the } .05 \text { level, two-sided test } \\
1 \text { each column represents a separate multivariate model in survival framework, with all rows as predictors controlling for age, age }{ }^{1} \text {, sex, cohorts, int } \\
\text { categories. Outcome variable indicated in each column header } \\
{ }^{2} \text { Group effect chi square is for the multi-df tests to assess any difference between all the disorders, while the individual chi-squares only tests yes vs no for } \\
\text { each disorder } \\
{ }^{3} \text { Group effect chi-square is for the multi-df tests to assess any difference between all the \# of disorder dummies, while the individual chi-squares only tests } \\
\text { yes vs no for each } \\
{ }^{4} \text { Denominator sample size of the models }\end{array}$} \\
\hline
\end{tabular}

disorders investigated in the present study predicted suicide attempts. This finding was consistent with previous studies from clinical settings ${ }^{21,22}$ and autopsy studies ${ }^{23,24}$ revealing that the vast majority of suicide attempters had a diagnosable mental disorder. However, the South African findings were slightly lower in comparison to the results from the National Comorbidity study in the United States where 66\% of respondents who seriously considered killing themselves and $80 \%$ who actually made a suicide attempt were found to have a prior mental disorder. ${ }^{25}$

Analysis that controlled for the confounding effects of other mental disorders showed that the effect of each individual mental disorder was lower than in a bivariate analysis, but almost always statistically significant. These findings may reflect the common factors that many disorders exhibit including distress and functional impairment, and their links to an escape model of suicide. ${ }^{26}$ After controlling for other mental disorders as confounders, the present study revealed that PTSD was the strongest predictor of suicide ideation and attempts. Previous studies have reported that depression was often the strongest psychiatric risk factor for suicide. ${ }^{25}$ The association with PTSD has been previously reported ${ }^{27,28}$ and may be particularly relevant in a country with a high prevalence of trauma, such as South Africa. ${ }^{29}$

Finally, the present study reveals that the presence of multiple disorders is associated with an increase in subsequent suicide attempt. This finding is consistent with a previous literature revealing that adults who had attempted suicide reported more than one mental disorder. ${ }^{13,30}$ However, more complex models reveal that the relationship between number of mental disorders and suicidal behaviour is not a linear progression, but rather that each additional disorder has a diminishing role. This effect in the interactive model was significantly different for unplanned suicidal attempt and suicidal ideation for individuals with exactly two disorders. It can be postulated that multi-morbidity is correlated with elevated levels of distress, impairment, and disease burden as indicated by previous studies conducted in the developed world. ${ }^{26,31}$ Similar to previous studies high levels of comorbidity may represent elevated_and perhaps intolerable-levels of distress and impairment, which some people may ultimately attempt to escape via suicide. Support for this model is provided by Nock et al. ${ }^{14}$ who report that the relation between multi-morbidity and suicidal behaviours is mediated by high levels of aversive emotional arousal.

Several important limitations should be emphasized when interpreting these results. First, the data are based on retrospective self-reports of the occurrence of the mental disorder and timing of suicidal behaviour - so that systematic recall bias may be present. ${ }^{32}$ Nevertheless systematic reviews have suggested that people can recall past experiences with sufficient accuracy to provide valuable information. ${ }^{33,34}$ It has also been shown that retrospective data are especially useful when prospective data are not available. ${ }^{35}$ Nonetheless, it is important to be cautious when interpreting the results because recall bias almost certainly exists to some extent in the retrospective reports. Second, although the data examined a 
wide range of mental disorders, several disorders known to be linked to suicidal behaviours were not included, most notably non-affective psychosis and personality disorders. Third, we did not examine some independent factors, such as genetic predisposition or stressful life events, which may increase the severity or chronicity of each disorder.

\section{Conclusion}

Despite limitations, the result of the present study provides further insight into the relationship between psychiatric disorders and suicidal behaviour in South Africa. It is hoped that these data can aid in the development of appropriate preventive interventions for those South Africans more at risk for suicide. Programmes in developed countries have emphasized the importance of comorbidity and analogous programs are necessary in South Africa.

\section{References}

1. Desjarlais R, Eisenberg L, Good B, Kleinman A. World Mental Health: Problems and Priorities in Low-Income Countries. Oxford: Oxford University Press; 1995.

2. WHO. World health report 2003: shaping the future. Geneva: World Health Organization; 2003

3. Kessler RC, Berglund P, Borges G, Nock M, Wang PS. Trends in suicide ideation, plans, gestures, and attempts in the United States, 1990-1992 to 2001-2003. J Am Med Assoc 2005;293:2487-95.

4. Kessler RC, Borges G, Walters EE. Prevalence of and risk factors for lifetime suicide attempts in the National Comorbidity Survey. Arch Gen Psychiatry 1999 ;56(7):617-26.

5. Joe S, Stein DJ, Seedat S, Herman A, Williams DR. Non-fatal suicidal behavior among South Africans : results from the South Africa StresS and Health Study. Soc Psychiatry Psychiatr Epidemiol 2008 ;43(6):454-61.

6. Harris EC, Barraclough B. Suicide as an outcome for mental disorders. A meta-analysis. British Journal of Psychiatry 1997; 170:205-28.

7. $\quad$ Ping Q, Merete N. Suicide Risk in Relation to Psychiatric Hospitalization: Evidence Based on Longitudinal Registers". Arch Gen Psychiatry 2005; 62:427-432.

8. Pilowsky DJ, Wu LT, Anthony JC. Panic attacks and suicide attempts in mid-adolescence. American Journal of Psychiatry 1999;156(10):1545-9.

9. Anthony JC, Petronis KR. Panic attacks and suicide attempts. Arch Gen Psychiatry 1991;48(12):1114.

10. Weismann MM, Bland RC, Canino GJ, Greenwald S, Hwu HGeal. Prevalence of suicide ideation and suicide attempts in nine countries. Psychological Medicine 1999;29:9-17.

11. Vijayakumar L. Suicide prevention: The urgent need in developing countries. World Psychiatry 2004;3:8159-159.

12. Nuruso SO, Odesamni WO. Patterns of Suicides in Ile-Ife Nigeria. West African Journal of Medicine 2001;20(3):259-62.

13. Ndosi NK, Mbonde MP, Lyamuya EL. Profile of Suicide in Dar es Salaam. East African Medical Journal 2004;81:207-11.

14. Nock MK, Borges G, Bromet EJ, Alonso J, Angermeyer M, Beautrais A, et al. Cross-national prevalence and risk factors for suicidal ideation, plans and attempts. Br J Psychiatry 2008 ; 192(2):98-105.

15. Borges G, Angst J, Nock MK, Ruscio AM, Kessler RC. Risk factors for the incidence and persistence of suicide-related outcomes: a 10-year follow-up study using the National Comorbidity Surveys. J Affect Disord 2008 ; 105(1-3):25-33.

16. Williams D, Sonnega J, Seedat S, Stein D, Moomal H, Wilson C. The
South African Stress and Health Study: Rationale and design. Metabolic Brain Disease 2004; 1 9:1 35-47.

17. Demyttenaere K, Bruffaerts R, Posada-Villa J, Gasquet I, Kovess V, Lepine JPeal. Prevalence, severity and unmet need for treatment of mental disorders in the World Health Organization World Mental Health (WMH) surveys. Journal of the American Medical Association 2004;291:2581-90

18. Kessler RC, Ustun TB. The World Mental Health (WMH) Survey Initiative Version of the World Health Organization (WHO) Composite International Diagnostic Interview (CIDI). International Journal of Methods in Psychiatric Research 2004;13(2):93-121.

19. Wolter KM. Introduction to variance estimation. New York, NY: Springer-Verlag; 1985.

20. SUDAAN Professional. Software for Survey Data Analysis [computer program]. Research Triangle Park, NC: Research Triangle Institute; 2002.

21. Cavanagh JT, Carson AJ, Sharpe M, Lawrie SM. Psychological autopsy studies of suicide: a systematic review. Psychological Medicine 2003;33(3):395-405

22. Shaffer D, Gould MS, Fisher P, Trautman P, Moreau D, Kleinman M, et al. Psychiatric diagnosis in child and adolescent suicide. Arch Gen Psychiatry 1996 ;53(4):339-48.

23. Beautrais AL, Joyce PR, Mulder RT, Fergusson DM, Deavoll BJ, Nightingale SK. Prevalence and comorbidity of mental disorders in persons making serious suicide attempts: a case-control study. Am J Psychiatry $1996 ; 1$ 53(8):1009-14.

24. Wunderlick U, Bronisch T, Wittchen HU. Comorbidity patterns in adolescents and young adults with suicide attempts. European Archives of Psychiatry and Clinical Neuroscience 1998;248(2):87-95.

25. Nock MK, Hwang I, Sampson NA, Kessler RC. Mental disorders, comorbidity and suicidal behavior: Results from the National Comorbidity Survey Replication. Mol Psychiatry 2009; 15(8):868-76.

26. Baumeister RF. Suicide as escape from self. Psychological Review 1990;97(1):90-113.

27. Oquendo M, Brent DA, Birmaher B, Greenhill L, Kolko D, Stanley B, et al. Posttraumatic stress disorder comorbid with major depression: factors mediating the association with suicidal behavior. Am J Psychiatry 2005 ; 162(3):560-6.

28. Oquendo MA, Friend JM, Halberstam B, Brodsky BS, Burke AK, Grunebaum MF, et al. Association of comorbid posttraumatic stress disorder and major depression with greater risk for suicidal behavior. Am J Psychiatry $2003 ; 160(3): 580-2$.

29. Stein DJ, Seedat S, Herman A, Moomal H, Heeringa SG, Kessler RC, et al. Lifetime prevalence pf psychiatric disorders in South Africa. British Journal of Psychiatry $2008 ; 192(2): 112-7$.

30. Slap GB, Vorters DF, Chaudhuri S, Centor RM. Risk factors for attempted suicide during adolescence. Pediatrics 1989;84:762-72.

31. Shneidman ES. Suicide as psychache. Journal of Nervous and Mental Disease 1993;181(3):145-7.

32. Angold A, Erkanli A, Costello EJ, Rutter M. Precision, reliability and accuracy in the dating of symptom onsets in child and adolescent psychopathology. Journal of Child Psychology and Psychiatry 1996;37(6):657-66.

33. Brewin CR, Andrews B, Gotlib IH. Psychopathology and early experience: a reappraisal of retrospective reports. Psychological Bulletin 1993;1 13(1):82-98.

34. Hardt J, Rutter M. Validity of adult retrospective reports of adverse childhood experiences: review of the evidence. Journal of Child Psychology and Psychiatry 2004;45(2):260-73.

35. Schlesselman Jj. Case-control studies: Design, conduct, and analysis. New York, NY: Oxford University Press; 1982. 